\title{
Nephrectomy in patients with Caroli's and ADPKD may be associated with increased morbidity
}

\author{
Martin Aguilar, MD, ${ }^{*}$ Sarkis Meterissian, MD, MSc, FRCSC, ${ }^{\dagger}$ Sebastien Levesque, MD, PhD, FRCPC;, \\ Sero Andonian, MD, MSc, FRCSC*
}

\section{Abstract}

Autosomal dominant polycystic kidney disease (ADPKD), characterized by multiple bilateral renal cysts, is the most common inherited disorder of the kidney and an important cause of endstage renal disease (ESRD). Caroli's disease is a much less frequent condition with ectasia of the intrahepatic biliary system. A clear association between autosomal recessive and Caroli's disease has been described, but only 4 cases of ADPKD and Caroli's disease have been reported with 2 postoperative mortalities. The aim of this case is to increase the awareness of intra-operative and postoperative complications. A 66 year-old male was diagnosed with ADPKD and Caroli's disease with hepatosplenomegaly and 4 episodes of ascending cholangitis. After 3 years of hemodialysis for ESRD, he received a cadaveric renal allograft. Subsequently, he developed paroxysmal atrial fibrillation. Upon anticoagulation, he developed multiple episodes of gross hematuria from the left native kidney. After the anticoagulation therapy was discontinued, he underwent bilateral nephrectomies of his native kidneys. Intra-operatively, a splenic laceration could not be managed conservatively. Therefore, splenectomy was performed. In addition, he developed ascending cholangitis post-operatively that was treated with antibiotics. He was discharged on postoperative day 18 . Genetic testing revealed that the patient is heterozygote for a large deletion in PKD1 gene, which encompasses all tested exons (exons 1-44).

Cite as: Can Urol Assoc J 2011;5(2):e19-e22; D01:10.5489/cuaj.10054

\section{Introduction}

Autosomal dominant polycystic kidney disease (ADPKD) is the most common inherited disorder of the kidney and the third most common cause of end-stage renal disease (ESRD). ${ }^{1}$ It is characterized by bilaterally enlarged kidneys containing multiple cysts. ${ }^{2}$ Caroli's disease is a much less frequent condition in which there is ectasia of the intrahepatic bile ducts. ${ }^{3}$ There is a well-established association between autosomal recessive polycystic kidney disease (ARPKD) and Caroli's disease, ${ }^{4}$ but only 4 case reports of ADPKD and Caroli's disease, with 2 reported postoperative mortalities (Table 1). The aim of the present article is to present such a case and increase awareness of intra-operative and postoperative complications.

\section{Case report}

A 66-year-old male initially presented in 2002 with ascending cholangitis and was found to have intrahepatic biliary duct dilatation consistent with Caroli's disease. In 2004, he developed ESRD secondary to ADPKD. After 3 years of hemodialysis, he received cadaveric (donor after cardiac death) renal transplantation with subsequent delayed graft function in April 2007. He was re-admitted in May 2007 with paroxysmal atrial fibrillation secondary to atrioventricular node re-entry tachycardia (AVNRT) requiring anticoagulation. Subsequently, he developed gross hematuria requiring blood transfusions. Investigations pointed to his left polycystic kidney as the source of the hematuria (Fig. 1). Therefore, his anticoagulation was discontinued. In July 2007 , he developed ascending cholangitis for the fourth time in 5 years. In December 2007, the patient was admitted with hemorrhagic left kidney cysts and left pyelonephritis. Of note, his prothrombin time (PT)/international normalized ratio (INR) was elevated due to vitamin $\mathrm{K}$ deficiency secondary to Caroli's disease-induced malabsorption of fat-soluble vitamins.

His medical history was also significant for arterial hypertension, hepatosplenomegaly with portal hypertension, hypercholesterolemia, iron deficiency anemia, mild aortic stenosis, osteoporosis (T-score $=-3.5$ standard deviation $[S D])$, sleep apnea and gout. His surgical history was also significant for appendectomy, bilateral inguinal hernia repair and spinal L3-4-5 disc prolapse repair. His medications included flecainide, metoprolol, ASA, colchicine, prednisone, mycophenolate mofetil, tacrolimus, spironolactone, furosemide, atorvastatin and vitamin D.

As far as his family history is concerned, the patient's father left the family and his mother's side is negative for ADPKD and Caroli's disease. He has 2 healthy half-siblings, none of whom are from the same father. He has 2 presumably healthy sons who refuse to be followed by a medical professional. In terms of his social history, he is an ex-smoker (smoked 40 pack-years). He quit 10 years ago. He consumes 


\begin{tabular}{|c|c|c|c|c|c|}
\hline & $\begin{array}{l}\text { Age at } \\
\text { ADPKD } \\
\text { diagnosis } \\
\text { (years) }\end{array}$ & $\begin{array}{l}\text { Age at } \\
\text { Caroli's } \\
\text { diagnosis } \\
\text { (years) }\end{array}$ & Past medical history & Procedure & Outcome \\
\hline Berenger et al. ${ }^{5}$ & 16 & 16 & $\begin{array}{l}\text { - Hepatitis at } 11 \text { months } \\
\text { - Asthma } \\
\text { - Hepatic cirrhosis } \\
\text { - Splenomegaly }\end{array}$ & $\begin{array}{l}\text { - Exploratory Laparoscopy, } \\
\text { - Splenectomy, } \\
\text { Cholecystectomy }\end{array}$ & $\begin{array}{l}\text { - Death } 4 \text { months } \\
\text { postoperative }\end{array}$ \\
\hline Jordon et al. ${ }^{6}$ & NA & 47 & $\begin{array}{l}\text { - 17-year history of recurrent } \\
\text { fever of unknown etiology } \\
\text { - Thyroid adenoma resection } \\
\text { - Hepatosplenomegaly } \\
\text { - Elective chelecystectomy for } \\
\text { chronic cholecystitis } \\
\text { - Loop colostomy for bowel } \\
\text { obstruction } \\
\text { - Bilateral nephrectomy and } \\
\text { Hemodialysis } \\
\text { - Kidney transplant rejection }\end{array}$ & - Exploratory Laparotomy & $\begin{array}{l}\text { - Pneumonia } \\
\text { - Chronic fibrous pericarditis } \\
\text { - Chronic pancolitis with } \\
\text { ulceration } \\
\text { - Postoperative sepsis and } \\
\text { death on 50th day }\end{array}$ \\
\hline Torra et al. ${ }^{7}$ & $\begin{array}{c}\text { As a } \\
\text { newborn }\end{array}$ & 23 & $\begin{array}{l}\text { - Pancytopenia at age } 18 \\
\text { - Hepatosplenomegaly } \\
\text { with right lobe Portal } \\
\text { cavernomatosis }\end{array}$ & $\begin{array}{l}\text { - Renal Biopsy } \\
\text { - Genetic evaluation } \\
\text { - (PKD1 mutation) }\end{array}$ & NA \\
\hline Shedda et al. ${ }^{8}$ & 40 & 73 & $\begin{array}{l}\text { - Hypercholesterolemia, } \\
\text { Hypertension } \\
\text { - Acute myocardial infarction } \\
\text { - Perforated sigmoid } \\
\text { diverticulitis } \\
\text { - Renal transplant } \\
\text { - Resection of multiple } \\
\text { skin squamous and basal } \\
\text { carcinomas }\end{array}$ & $\begin{array}{l}\text { - Left lateral segmentectomy } \\
\text { - Cholescystectomy }\end{array}$ & $\begin{array}{l}\text { - Postoperative E Coli } \\
\text { infection } \\
\text { - Hematoma } \\
\text { - Atrial fibrillation }\end{array}$ \\
\hline Present case & 60 & 58 & $\begin{array}{l}\text { - Appendectomy, bilateral } \\
\text { inguinal hernia repair } \\
\text { - Spinal L3-4-5 disc prolapse } \\
\text { repair } \\
\text { - Arterial hypertension, } \\
\text { portal hypertension, } \\
\text { hypercholesterolemia, iron } \\
\text { deficiency anemia, gout, } \\
\text { obstructive sleep apnea } \\
\text { - Hemodialysis for } 3 \\
\text { years followed by renal } \\
\text { transplantation } \\
\text { - Ascending cholangitis } \\
\text { (4 episodes in } 5 \text { years) } \\
\text { - Paroxysmal atrial } \\
\text { fibrillation and mild aortic } \\
\text { stenosis (anticoagulation } \\
\text { discontinued because of } \\
\text { hematuria) } \\
\text { - Hemorrhagic left renal cyst } \\
\text { and pyelonephritis } \\
\text { - Large deletion in PKD1 gene } \\
\text { (exons 1-44) }\end{array}$ & $\begin{array}{l}\text { - Bilateral nephrectomy } \\
\text { - Splenectomy }\end{array}$ & $\begin{array}{l}\text { - Postoperative ascending } \\
\text { cholangitis } \\
\text { - Patient discharged on } \\
\text { postoperative day } 18\end{array}$ \\
\hline
\end{tabular}




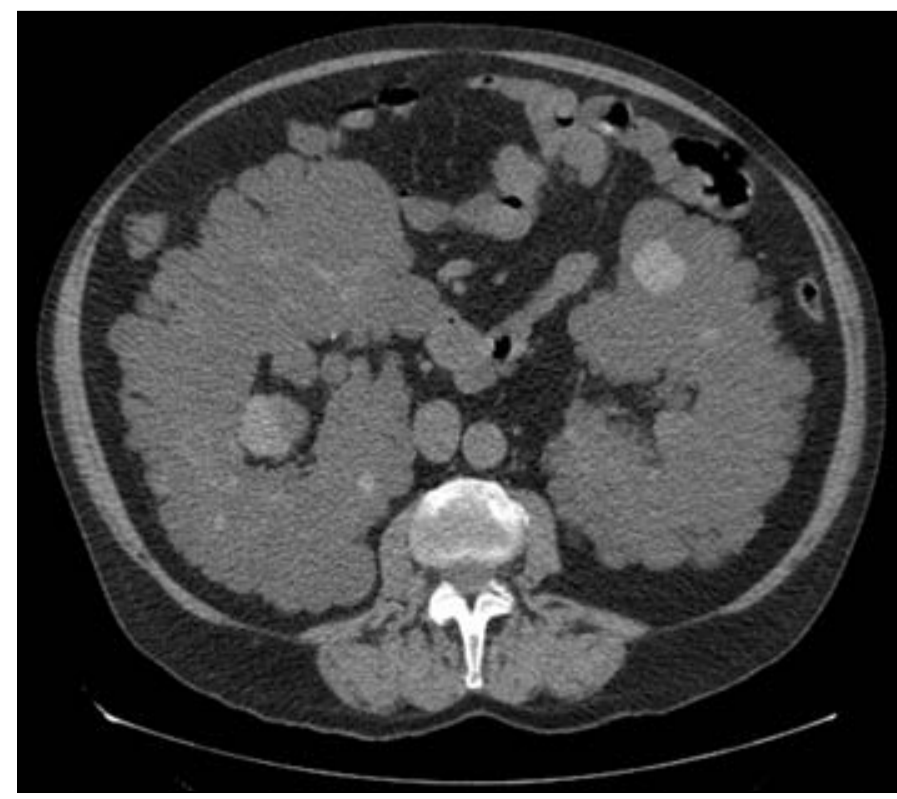

Fig. 1. A computed tomography scan of the abdomen showing polycystic kidney disease with few hemorrhagic cysts.

alcohol moderately, with a glass of wine with dinner and 2 beers per week.

On examination, he was found to have protuberant abdomen with mild tenderness in the left flank. Abdominal scar of the renal graft on the right lower quadrant was noted. His laboratory test showed slightly elevated gamma glutamyl transferase of $140 \mathrm{U} / \mathrm{L}(0-40)$, alkaline phosphatase of $272 \mathrm{U} / \mathrm{L}$ (25-115) and prothrombin time of $14.7 \mathrm{sec}$ (12.214.6). His baseline creatinine was $145 \mathrm{umol} / \mathrm{L}$ (55-110) and hemoglobin of $116 \mathrm{~g} / \mathrm{L}$ (140-180). His abdominal computed tomography scan showed enlarged polycystic kidneys (right larger than left) with several hemorrhagic cysts (Fig. 1).

In February 2010, the patient underwent bilateral nephrectomy of the native kidneys for recurrent gross hematuria, left pyelonephritis and left flank pain (Fig. 2). This procedure was performed through a midline incision. Intra-operatively, while mobilizing the splenic flexure, a splenic laceration was noted. Initially, this was managed conservatively by tamponade, Surgicel oxydized cellulose polymer (Ethicon, Markham, ON) and FloSeal hemostatic matrix (Baxter, Mississauga, ON). However, when conservative measures failed, a splenectomy was performed. Bilateral native nephrectomies were completed. Postoperatively, he developed right upper quadrant pain and fever. All cultures were negative. Liver magnetic resonance imaging was consistent with ascending cholangitis. He was treated with intravenous ciprofloxacin and metronidzole. He recovered and was discharged on postoperative day 18 . Genetic testing revealed that the patient is heterozygote for a large deletion in PKD1 gene, which encompasses all tested exons (exons 1-44).

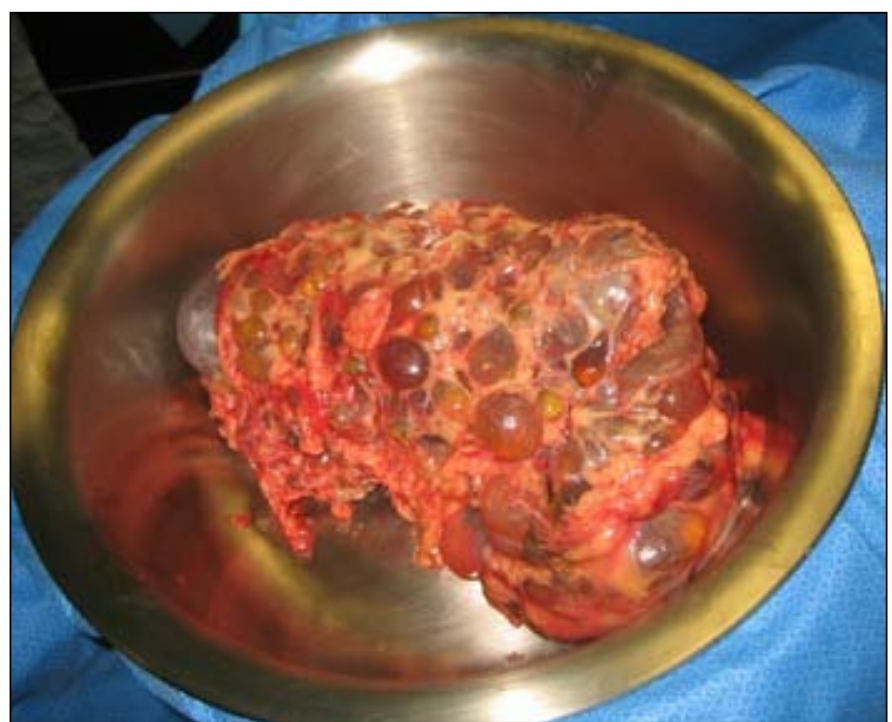

Fig. 2. A photograph of the left kidney after nephrectomy showing the large specimen of $20 \mathrm{~cm}$ with prominent cysts replacing most of the kidney.

\section{Discussion}

Autosomal dominant polycystic kidney disease is the most common inherited disorder with an estimated incidence between 1 in 400 to 1000 live births. ${ }^{9}$ It is characterized by multiple bilateral renal cysts and polycystic liver disease, one of the hepatobiliary fibropolycystic diseases characterized by overgrowth of biliary epithelium and supportive connective tissue. ${ }^{5}$ Other common extrarenal manifestations include cysts in the seminal vesicles, pancreas and arachnoid membrane in addition to intracranial Berry aneurysms of the circle of Willis. ${ }^{1}$ Clinically, symptoms of ADPKD include abdominal discomfort, hematuria, urinary tract infection, hypertension and elevated serum creatinine. ${ }^{12}$ Patients are usually asymptomatic until the fourth decade of life, after which renal function starts to decline; consequently, most patients need renal replacement therapy or transplantation.

Two genes account for the vast majority of ADPKD cases: polycystic kidney disease (PKD)1 on chromosome 16 (85\% of cases) and PKD2 on chromosome 4 (5\%-10\% of cases). Other yet unmapped mutations account for the remaining $5 \%$ to $10 \%$ of cases. ${ }^{6}$ PKD1 and PKD2 code for 2 membrane glycoproteins, polycystin-1 and polycystin-2, respectively. ${ }^{1}$ It is believed that the polycystins are important during renal embriogenesis. PKD1 is thought to be implicated in receptor and cell adhesion functions, while PKD2 is a calcium channel. ${ }^{1}$ Mutations in PKD1 and/or PKD2 lead to abnormal polycystin proteins causing increased fluid secretion, proliferation and cyst formation. ${ }^{1}$

Caroli's disease is much less common than ADPKD. Estimates suggest that $25 \%$ to $50 \%$ of cases could be autosomal recessive, the balance being sporadic, although no clear genetic basis for the disease has been identified. ${ }^{5}$ 
Aguilar et al.

Caroli's disease is characterized by segmental dilatation of the intrahepatic bile ducts without hepatic fibrosis as compared to Caroli's syndrome, which is defined as ectasia of the intrahepatic bile ducts with hepatic fibrosis. ${ }^{6,7}$ Clinically, patients with Caroli's disease often develop portal hypertension, fat-soluble vitamin deficiency (vitamin $\mathrm{K}$ in particular) and are at increased risk for intrahepatic stones and severe septic cholangitis.

It is thought that Caroli's disease is due to abnormal embriogenesis of the intrahepatic bile ducts. ${ }^{6}$ Intrahepatic biliary system develops by a 2-step transformation of the embryological hepatocytes; the first step leads to the formation of the ductal plates and the second to the formation of the primitive tubular bile ducts. ${ }^{8}$ Therefore, partial arrest or erroneous formation of the ductal plate and subsequent embryological structures are believed to be the basis of the disease.

The association between ARPKD and Caroli's disease is well-established. ${ }^{5}$ However, only very few cases of ADPKD with concomitant Caroli's disease have been reported. ${ }^{6,7,10,11}$ No clear explanation for this association has been found. ${ }^{5}$ Some studies suggest that polycystin-1, the glycoprotein coded by PKD1 might also be involved in the embryogenesis of the intrahepatic biliary system; therefore, specific mutations in the gene could explain both the ADPKD and Caroli's disease phenotypes. More specifically, some authors argue that both diseases could be the result of the abnormal formation of the ductal plate during embryological development. ${ }^{5,6}$ Others suggest that the low frequency of ADPKD with Caroli's disease could be due to a diagnostic dilemma. ${ }^{5}$ Indeed, polycystic liver disease is often present with ADPKD and could mask mild or moderate Caroli's disease. ${ }^{5}$ Furthermore, late state ARPKD can be radiologically similar to ADPKD, hence patients could be misdiagnosed with the recessive type PKD. ${ }^{1}$ However, it is essential to accurately diagnose Caroli's disease since partial hepatectomy can be curative if the disease is confined to a lobe. ${ }^{5}$ Failure to recognize the presence of the disease could allow progression of the condition and prevent proper patient care.

Four case reports of patients with ADPKD and Caroli's disease have been found (Table 1). ${ }^{6,7,10,11}$ It is important to note that for the 3 patients with clinical course, there were 2 postoperative mortalities and the third patient developed postoperative $E$. Coli infection and atrial fibrillation. We believe our present case is the fifth case report of ADPKD and Caroli's disease associated with increased morbidity, including intra-operative splenectomy and postoperative ascending cholangitis. Therefore, urologists should take these into consideration when offering nephrectomy to these patients.

*Division of Urology, McGill University Health Centre, Montreal, QC; † Division of Surgical Oncology, Department of Surgery, McGill University Health Centre, Montreal, QC; ${ }^{ \pm D e p a r t m e n t ~ o f ~ M e d i c a l ~}$ Genetics, McGill University Health Centre, Montreal, QC

Acknowledgements: This work was supported in part by the Northeastern AUA Young Investigator Award and Montreal General Hospital Foundation Award to Sero Andonian.

Competing interests: None declared.

This paper has been peer-reviewed.

\section{References}

1. Torres VE, Harris PC. Mechanisms of disease: autosomal dominant and recessive polycystic kidney disease. Nat Clin Pract Nephrol 2006;2:40-55.

2. Kumar V, Abbas AK, Fausto N. Robbins and Cotran pathologic basis of disease. In: The Kidney. 7th edition. Philadelphia, PA: Elsevier Saunders; 1999:962-4.

3. Pezzilli R, Carini G, Cennemo V. Hepatobiliary and pancreatic: Caroli's disease. J Gastroenterol Hepatol 2008;23:1621.

4. Shorbagi A, Bayraktar Y. Experience of a single center with congenital hepatic fibrosis: a review of the literature. World I Gastroenterol 2010;16:683-90.

5. Mousson C, Rabec M, Cervueil JP, et al. Caroli's disease and autosomal dominant polycystic kidney disease: a rare association? Nephrol Dial Transplant 1997;12:1481-3.

6. Torra R, Badenas C, Darnell A, et al. Autosomal dominant polycystic kidney disease with anticipation and Caroli's disease associated with a PKD1 mutation. Kidney Int 1997;52:33-8.

7. Shedda S, Robertson A. Caroli's syndrome and adult polycystic kidney disease. Anz I Surg 2007;77:292-4.

8. Ruebner BH, Blankenber TA, Burrows DA, et al. Development and transformation of the ductal plate in the developing human liver. Pediatr Pathol 1990(1-2):55-68.

9. Garcia Iglesias C, Torres VE, Offord KP, et al. Epidemiology of adult polycystic kidney disease. Am J Kidney Dis 1983;2:630-9.

10. Jordon D, Harpaz N, Thung SN. Caroli's disease and adult polycystic kidney disease: a rarely recognized association. Liver 1989:9:30-5.

11. Berenger J, Olaso V, Rayon M, et al. Dilatacion congenital no obstructive de los condoctos biliares intrahepaticos segmentarios (enfermedad de Caroli): presentacion de una observacion y revision de la literature. Rev Clin Esp 1976;140:567-77.

Correspondence: Dr. Sero Andonian, Assistant Professor of Urology, Royal Victoria Hospital, McGill University Health Centre, 687 Pine Ave West, Suite S6.92, Montreal, QC H3A 1A1; fax: 514-8431552; sero.andonian@muhc.mcgill.ca 